\title{
Prognostic Factors of Comas in the Intensive Care Unit of the University Teaching Hospital of Parakou (Benin)
}

\author{
Tchaou Blaise Adelin 1*, Adoukonou Thierry Armel2 ${ }^{2}$ Zoumenou Eugene ${ }^{3}$, \\ Mehou Loko Ulrich Donald ${ }^{4}$, Lokossou C. Thomas ${ }^{3}$ \\ ${ }^{1}$ Unité d’Enseignement et de Recherche de Anesthésie Réanimation, Faculté de Médecine, Université de \\ Parakou, Parakou, Benin \\ ${ }^{2}$ Unité d’Enseignement et de Recherche de Neurologie, Faculté de Médecine, Université de Parakou, Parakou, \\ Benin \\ ${ }^{3}$ Unité d’Enseignement et de Recherche de Anesthésie Réanimation, Faculté des Sciences de la Santé, \\ Université d'Abomey-Calavi, Abomey-Calavi, Benin \\ ${ }^{4}$ Service d'Anesthésie Réanimation du Centre Hospitalier, Universitaire Départemental de Parakou, Parakou, \\ Benin \\ Email: ${ }^{*}$ tchblaise@yahoo.fr
}

Received 24 August 2015; accepted 19 October 2015; published 22 October 2015

Copyright (C) 2015 by authors and Scientific Research Publishing Inc.

This work is licensed under the Creative Commons Attribution International License (CC BY). http://creativecommons.org/licenses/by/4.0/

(c) (i) Open Access

\section{Abstract}

Background: Coma is a highly frequent situation associated with several diseases. Objective: That is to assess the prognostic factors of comas at the intensive care unit of the university teaching hospital of Parakou. Patients and Methods: It is a cross-sectional study with descriptive and analytical purpose based on prospective gathering of data. It has been performed from March 1 to July 31,2014 . The population study consists of 100 adult patients admitted to the intensive care unit for coma. The vital and functional prognosis data are studied. Results: The admission frequency of comatose patients to the intensive care unit is $44.4 \%$. Patients' mean age is $27 \pm 13.9$ years with extremes of 16 and 88 years. The average length of stay in the intensive care unit is $5.2 \pm 5.6$ days with extremes of 2 hours 30 minutes and 30 days. Mortality rate is $30 \%$. Poor prognostic factors are: average Glasgow score of $6.8 \pm 2.9(p=0.01)$, average outpatient simplified severity index (OSSI) of $9.1 \pm 3.5(p=0.02)$, pupillary abnormality $(p=0.00)$, motor weakness $(p=0.00)$, average glycemia of $1.5 \pm 0.82 \mathrm{~g} / \mathrm{L}(p=0.02)$, average systolic blood pressure of $130.9 \pm 44.5 \mathrm{~mm} \mathrm{Hg}(p=$ $0.03)$, average diastolic blood pressure of $80.8 \pm 22.3 \mathrm{~mm} \mathrm{Hg}(p=0.03)$, average respiratory rate of $30.9 \pm 10.6 \mathrm{cycles} / \mathrm{min}(p=0.03)$ and average temperature of $37.8^{\circ} \mathrm{C} \pm 1.2^{\circ} \mathrm{C}(p=0.03)$. Conclusion: Coma is a pathological entity with high frequency in clinical medicine. Its positive diagnosis is easy,

${ }^{*}$ Corresponding author.

How to cite this paper: Adelin, T.B., Armel, A.T., Eugene, Z., Donald, M.L.U. and Thomas, L.C. (2015) Prognostic Factors of Comas in the Intensive Care Unit of the University Teaching Hospital of Parakou (Benin). Journal of Behavioral and Brain Science, 5, 503-512. http://dx.doi.org/10.4236/jbbs.2015.511048 
but etiological research is hard. Hospital mortality is high and influenced by several factors. Taking into account, those factors in care strategies can improve their prognosis.

\title{
Keywords
}

\author{
Coma, Prognostic Factors, Morbidity, Mortality
}

\section{Introduction}

Coma is defined as the alteration of vigilance and consciousness. It is a highly frequent situation associated with several diseases. It raises complicated problems to solve them. A good understanding of semiology and a veritable diagnostic and therapeutic strategy are required.

The epidemiological importance of this pathological entity is noted in developed countries, especially in France where annual incidence is 150 to 300 hospitalized persons out of 100,000 inhabitants. There are about 150,000 persons with traumatic brain injury. Approximately 8000 deaths and 4000 comas are registered every year [1].

In Africa and more particularly in Senegal, in 2007 Soumaré et al. reported 51\% of mortality among 305 patients hospitalized for coma [2] in a study conducted in the Infectious Disease Clinic of the University Teaching Hospital (CHU) of Dakar-Fann. As well, in Tunisia, Kammoun et al. carried out a study in the emergency intensive care unit of Habib Bourguiba Hospital of Sfax, where they registered 56.9\% of death among 137 patients admitted for coma in 2009 [3]. In Côte d'Ivoire, Konan et al. disclosed 52.2\% of death in a study conducted in 2011 [4] at the University Teaching Hospital of Yopougon.

In Benin, a survey conducted on coma by Moussa in 2007 at CNHU-HKM (Centre National Hospitalier Universitaire Hubert Koutoukou MAGA) in Cotonou was enabled to note an admission frequency of $11.2 \%$ with $58.7 \%$ of lethality [5]. In that research work age, sex and coma etiology had been identified as poor prognostic factors. The figures just above were testimonies of how severe the situation was; they therefore prompted us to perform this work which aimed to assess coma prognostic factors in the intensive care unit of the university teaching hospital of Parakou.

\section{Patients and Methods}

The study took was performed in the intensive care unit of the university teaching hospital of Parakou (Benin). It was a cross-sectional, descriptive and analytical study based on prospective gathering of data; it was conducted from March 1 to July 31, 2014. The institutional ethical committee approved it. The study population consisted of all adult patients admitted to the intensive care unit in a state of coma. We used an exhaustive approach for the selection of all comatose patients whatever the etiology of coma is. This survey involved all the patients above 15 years of age in a comatose state (Glasgow scale lower than fifteen) admitted to the intensive care unit. The comatose patients who died on admission before any care were excluded. The data collection techniques used were document review (use of referral or transfer sheet and emergency information sheet) and medical observation as regards data obtained in the intensive care unit (data related to clinical and paraclinical examination and to patient's condition on discharge from the intensive care unit). A standardized data collection slip served as a medium for gathering. The assessment criteria established were:

- Prognosis is patient's condition on discharge from the intensive care unit. It is a dichotomous variable with two categories or levels: alive $=1$, dead $=0$.

- As assessment criterion of minor importance there is patient's condition on discharge from the unit; this is assessed based on the Rankin scale (level of disability or of dependence).

The study variables were:

The dependent variable

This is the main assessment criterion which is patient's condition at the end of care in the intensive care unit. It consists of two levels or categories (alive $=1$, dead $=0$ ). The secondary endpoint criterion is the level of disability appraised on the Rankin scale. A patient is classified as dependent if the Rankin score is $>2$ and as independent if RANKIN $<2$. 
The independent variable

These are socio-demographic data (age, sex, occupation), clinical data (type of coma, context of occurrence, waiting time for admission, systolic blood pressure (SBP), diastolic blood pressure (DBP), temperature $\left(\mathrm{T}^{\circ}\right)$, pulse, neurological examination and examination of the other apparatuses, OSSI) and paraclinical data (scanner, biology) and factors impeding management of care, evolution and prognosis.

Statistical analysis

Statistical analysis was performed by using Epi-Info 3.5.1 software. Usual descriptive analysis was used: means and standard deviations to describe quantitative variable, proportions for qualitative variable. To study the factors associated to the prognosis bivariate analysis were performed. Chi-2 test or Fisher's exact test was used to compare the different proportions and Student T test to compare means. $p<0.05$ was considered to be statistically significant.

Ethical issues

The study was approved by the authorities of the hospital and anonymity and confidentiality were observed.

\section{Results}

\subsection{Socio-Demographic Data}

During the study period, 225 patients were hospitalized in the intensive care unit. Among them we colligated 100 cases of coma representing $44.4 \%$ of admissions. Patients' mean age was $43.9 \pm 19.6$ years with extremes of 16 and 88 years. The most represented age group is the one of patients aged 16 and 35 years (43\%) and male predominance (66\%) had been noted with a sex ratio of 1.9. In our cohort, the following occupations were identified: independent employees (58\%), housewives (21\%), university and secondary school students (11\%), civil servants (8\%) and the jobless (2\%). Sixty-five percent of patients were admitted to the intensive care unit in less than 24 hours after the onset of coma and 35\% of the patients had consulted 48 hours after the onset of coma.

\subsection{Clinical and Paraclinical Data}

In our cohort, $58 \%$ of the patients had been directly admitted to the intensive care unit against $29 \%$ of patients referred from another health center and 13\% of patients had been transferred from another unit of the hospital. No patient benefited from medical transportation. Fifty-three percent of patients were carried with a public transit vehicle, $18 \%$ were brought by motorcycle and $16 \%$ were transported by firefighters. Coma suddenly occurred in $69 \%$ of the cases. In our cohort, $47 \%$ of patients had consulted a healthcare practice or a traditional healer before being admitted to the intensive care unit. Among them $30 \%$ had consulted a healthcare practice, $9 \%$ had consulted at the same time a healthcare practice and a traditional healer and $8 \%$ had consulted only a traditional healer. The reasons for admission to the intensive care unit were varied. The data of patients' physical examination were the following. Glasgow Coma Scale or Score (GCS) was computed for each patient. GS $<8$ in $33 \%$ of the cases; its value is comprised between 8 and 12 in $49 \%$ of the cases and $\geq 13$ in $18 \%$ of the cases. Table 1 indicates distribution of patients according to the other data of physical examination on admission.

Table 2 displays the distribution of patients according to neurological data. These data provide information on pupillary abnormalities and on the existence or not of motor deficit on admission.

Table 3 shows the distribution of patients according to blood test results.

Table 1. Distribution of patients according to the other data of physical examination.

\begin{tabular}{ccc}
\hline & Mean $\left(+/-\mathrm{SD}^{*}\right)$ & {$[\text { Min }- \text { Max }]^{*}$} \\
\hline Temperature & $37.3(+/-0.9)$ & {$[35.5-41]$} \\
Pulse & $100.9(+/-24.9)$ & {$[45-180]$} \\
Systolic blood pressure (SBP) & $131.2(+/-38)$ & {$[60-260]$} \\
Diastolic blood pressure (DBP) & $81.4(+/-21.9)$ & {$[40-160]$} \\
Respiratory rate (RR) & $27.7(+/-9.3)$ & {$[8-62]$} \\
Glasgow scale & $8.8(+/-3.1)$ & {$[3-13]$} \\
Outpatient simplified severity index (IGSA) & $6.1(+/-3.6)$ & {$[0-15]$} \\
\hline
\end{tabular}

*SD: standard deviation, Min: Minimum, Max: Maximum. 
Table 2. Distribution of patients according to neurological data on admission.

\begin{tabular}{lc}
\hline Condition of pupils & Number (Percentage) \\
Normal & $71(71)$ \\
Unilateral mydriasis & $16(16)$ \\
Bilateral miosis & $7(7)$ \\
Bilateral mydriasis & $6(6)$ \\
Motor activity & \\
Normal & $67(67)$ \\
Hemiparesis & $7(7)$ \\
Hemiplegia & $6(6)$ \\
Tetraplegia & $1(1)$ \\
No motor activity in the limbs without spinal cord injury & $19(19)$ \\
\hline
\end{tabular}

Table 3. Distribution of patients according to blood test results.

\begin{tabular}{|c|c|c|}
\hline & Mean $(+/-\mathrm{SD})$ & [Min-Max] \\
\hline Glycemia & $1.5(+/-0.8)$ & {$[0.15-4.8]$} \\
\hline Uremia & $0.4(+/-0.3)$ & {$[0.05-2.3]$} \\
\hline Creatininemia & $21.5(+/-27.9)$ & {$[6-198.7]$} \\
\hline Natremia & $135.9(+/-8.9)$ & {$[109-168.2]$} \\
\hline Kaliemia & $3.7(+/-0.8)$ & {$[1.4-7.6]$} \\
\hline Chloremia & $102.8(+/-7.9)$ & {$[80-142.9]$} \\
\hline Calcemia & $86.5(+/-6.7)$ & {$[79.9-100]$} \\
\hline Blood smear/parasite density & $3875.4(+/-9729.0)$ & {$[200-45,000]$} \\
\hline Number of white blood cells & $12057(+/-5577.0)$ & {$[6000-31,400]$} \\
\hline Hemoglobin level & $11.7(+/-2.4)$ & {$[5.3-16.7]$} \\
\hline Transferase Glutamopyruvate (TGP) & $89.02(+/-59.8)$ & {$[46-180]$} \\
\hline Transferase Glutamooxaloacetate (TGO) & $84.5(+/-45.6)$ & {$[48-147]$} \\
\hline
\end{tabular}

*SD: standard deviation, Min: Minimum, Max: Maximum.

Table 4. Distribution of patients according to type of coma.

\begin{tabular}{cc}
\hline & Number/Percentage \\
\hline Traumatic comas & $\mathbf{4 3}(\mathbf{4 3})$ \\
Traumatic brain injury (TBI) & $35(35)$ \\
Multiple traumas & $8(8)$ \\
Non-traumatic comas & $\mathbf{5 7}(\mathbf{5 7})$ \\
Vascular & $24(24)$ \\
Infectious & $14(14)$ \\
Metabolic & $13(13)$ \\
Toxic & $2(2)$ \\
Postictal (epilepsy) & $2(2)$ \\
Others & $2(2)$ \\
\hline
\end{tabular}

Brain scanner was performed in 34\% of the cases and it results in the following outcomes: epidural hematoma (11\%); cerebral contusion (11\%); intraparenchymal hemorrhage (3\%); cerebral ischemia (3\%); acute subdural hematoma (2\%); intraparenchymal hemorrhage + aneurysm rupture (1\%); intra-parenchymal hemorrhage + subarachnoid hemorrhage $(1 \%)$ and brain edema (1\%). Brain scanner was normal in $1 \%$ of the cases.

Table 4 shows the distribution of patients according to the type of coma. 


\subsection{Therapeutic Data: Factors Impeding Therapeutic Management in the Intensive Care Unit}

Some factors impeded the provision of care for patients in the intensive care unit. In our sample, $78 \%$ of parents had paid all drugs prescribed by physicians whereas $22 \%$ only paid a part of it. As regards time limit, $40 \%$ of parents paid the drugs prescribed by physicians with delay. The drugs were available in the hospital but the patients didn't pay them because of the lack of money. Most of them didn't pay the brain CT-scan (the cost of it is 90 dollars US). It delayed the best management of patients. The biological tests weren't usually done in all patients. Those factors limited the care of the patients and could explain part of the prognosis.

\subsection{Evolution and Prognostic Data}

The average length of stay in the intensive care unit was $5.2 \pm 5.6$ days, with extremes of 2 hours 30 min and 720 hours (30 days). In our cohort $70 \%$ of the patients were cured while $30 \%$ had died. Sixty percent of deaths occurred in less than 48 hours after hospitalization in the intensive care unit. Among the patients alive, 67 were transferred to another unit (67\%) and 3 patients went back home against advice (3\%). Among the 67 patients (67\%) transferred from the intensive care unit, 61 patients were independent with one RANKIN $\leq 2(61 \%)$ and 6 patients were dependent with one RANKIN $>2$ (6\%). In the transfer/referral unit, 56\% of the patients were cured with no neurological sequelae, $10 \%$ of them were cured with neurological sequelae and one patient died $(1 \%)$.

\subsection{Factors Influencing Vital Prognosis}

Most factors influenced the vital prognosis. The patient who had the lower score in GCS, those who had a fever, high OSSI, pupils abnormality and a motor weakness. Other factors influenced the vital prognosis such as glycaemia, delay in paying drugs and the lack of drugs, the length of hospital stay. The patients who had a low length of stay had more risk of death and those with neurological impairment (pupil abnormality, motor weakness...) had had a high proportion of death. Specifically the association between those factors and the death are summarized in Tables 5-9.

Table 5 indicates the distribution of dead patients according to physical examination data.

Table 5. Distribution of dead patients according to physical examination data.

\begin{tabular}{cccc}
\hline & Alive & Dead & $\boldsymbol{p}$ \\
Glasgow & & & $\mathbf{0 . 0 1}$ \\
Average (+/-SD) & $9.8(+/-2.6)$ & $6.83(+/-2.9)$ & \\
[Min - Max] & {$[03-13]$} & {$[03-13]$} & \\
IGSA & & $9.1(+/-3.5)$ & $\mathbf{0 . 0 2}$ \\
Average (+/-SD) & $4.8(+/-2.9)$ & {$[03-15]$} & \\
[Min - Max] & {$[0-12]$} & $37.8(+/-1.2)$ & $\mathbf{0 . 0 3}$ \\
Temperature & & {$[36-41]$} & \\
Average (+/-SD) & $37.1(+/-0.8)$ & & $\mathbf{0 . 0 3}$ \\
[Min - Max] & {$[35.5-39.5]$} & $130.9(+/-44.5)$ & \\
TAS & $131.4(+/-35.3)$ & {$[78-260]$} & $\mathbf{0 . 0 3}$ \\
Average (+/-SD) & {$[60-240]$} & $80.8(+/-22.3)$ & \\
[Min - Max] & & {$[55-150]$} & \\
TAD & $81.7(+/-21.8)$ & & $\mathbf{0 . 2}$ \\
Average (+/-SD) & {$[40-160]$} & $105.8(+/-29.3)$ & \\
[Min - Max] & & {$[50-180]$} & \\
Pulse & $98.8(+/-22.8)$ & $30.9(+/-10.6)$ & {$[08-62]$} \\
Average (+/-SD) & {$[45-180]$} & $\mathbf{0 . 0 3}$ \\
[Min - Max] & $26.3(+/-8.5)$ & {$[16-50]$} & \\
FR & &
\end{tabular}

*SD: standard deviation, Min: Minimum, Max: Maximum. 
Table 6 shows the distribution of dead patients according to neurological data.

Table 7 shows the distribution of dead patients according to data on glycemia results, kidney test and Electrolyt count.

Table 8 shows the distribution of dead patients according to factors impeding therapeutic management in the intensive care unit.

The distribution of dead patients according to duration of hospitalization in the intensive care unit is recorded in Table 9.

\section{Discussion}

\subsection{Clinical and Paraclinical Data}

Most patients involved in this survey were directly admitted to the emergency unit before being transferred to

Table 6. Distribution of dead patients according to neurological data.

\begin{tabular}{|c|c|c|c|}
\hline & Alive (\%) & Dead (\%) & $p$ \\
\hline Condition of pupils & & & $\mathbf{0 . 0 0}$ \\
\hline Normal $(n=71)$ & $59(83.1)$ & $12(16.9)$ & \\
\hline Unilateral mydriasis $(n=16)$ & $6(37.5)$ & $10(62.5)$ & \\
\hline Bilateral miosis $(n=7)$ & $3(42.9)$ & $4(57.1)$ & \\
\hline Bilateral mydriasis $(n=6)$ & $2(33.3)$ & $4(66.7)$ & \\
\hline Motor activity & & & $\mathbf{0 . 0 0}$ \\
\hline Normal $(n=67)$ & $55(82.1)$ & $12(17.9)$ & \\
\hline Hemiparesis $(n=7)$ & $6(85.7)$ & $1(14.3)$ & \\
\hline Hemiplegia $(n=6)$ & $4(66.7)$ & $2(33.3)$ & \\
\hline Tetraplegia $(n=1)$ & $0(0)$ & $1(100)$ & \\
\hline No motor activity in the limbs without spinal cord injury $(n=19)$ & $5(26.3)$ & $14(73.7)$ & \\
\hline
\end{tabular}

Table 7. Distribution of dead patients according to data on glycemia results, kidney test and Electrolyt count.

\begin{tabular}{|c|c|c|c|}
\hline & Alive & Dead & $p$ \\
\hline Glycemia & & & 0.02 \\
\hline Average (+/- SD) & $1.7(+/-0.39)$ & $1.5(+/-0.82)$ & \\
\hline [Min - Max] & {$[0.26-4.8]$} & [0.15 - 3.9] & \\
\hline Blood urea & & & 0.4 \\
\hline Average (+/- SD) & $0.39(+/-0.3)$ & $0.5(+/-0.3)$ & \\
\hline [Min - Max] & [0.05 - 2.34] & {$[0.2-1.3]$} & \\
\hline Creatininemia & & & 0.1 \\
\hline Average (+/- SD) & $18.7(+/-27.7)$ & $24.9(+/-26.6)$ & \\
\hline [Min - Max] & [06 - 198.7] & [06 - 127.5] & \\
\hline Natremia & & & 0.3 \\
\hline Average (+/- SD) & $135.7(+/-8.5)$ & $134.6(+/-11.8)$ & \\
\hline [Min - Max] & [109 - 168,2] & [109.1 - 168.2] & \\
\hline Kaliemia & & & 0.07 \\
\hline Average (+/- SD) & $3.6(+/-0.7)$ & $3.5(+/-0.8)$ & \\
\hline [Min - Max] & {$[2.7-7.6]$} & {$[0.14-5.1]$} & \\
\hline Chloremia & & & 0.09 \\
\hline Average (+/- SD) & $102.7(+/-8.4)$ & $103.1(+/-10.7)$ & \\
\hline [Min - Max] & [80 - 142.9] & [84.4 - 142.9] & \\
\hline
\end{tabular}


Table 8. Distribution of dead patients according to factors impeding therapeutic management in the intensive care unit.

\begin{tabular}{|c|c|c|c|}
\hline & Alive (\%) & Dead (\%) & $p$ \\
\hline Delay in paying drugs prescribed by physicians & & & 0.00 \\
\hline Yes $(n=40)$ & $21(52.5)$ & $19(47.5)$ & \\
\hline No $(n=60)$ & $49(81.7)$ & $11(18.3)$ & \\
\hline All prescribed drugs paid & & & 0.03 \\
\hline Yes $(n=78)$ & $59(75.6)$ & $19(25.4)$ & \\
\hline No $(n=22)$ & $11(50)$ & $11(50)$ & \\
\hline
\end{tabular}

Table 9. Distribution of dead patients according to duration of hospitalization in the intensive care unit.

\begin{tabular}{cccc}
\hline & Alive & Dead (\%) & p \\
\hline $24 \mathrm{~h}(n=6)$ & 1 & $5(83.3)$ & $\mathbf{0 . 0 0}$ \\
$24 \mathrm{~h}-48 \mathrm{~h}(n=28)$ & 15 & $13(46.4)$ & $2(18.12)$ \\
$48 \mathrm{~h}-72 \mathrm{~h}(n=11)$ & 9 & $6(18.7)$ \\
3 days -7 days $(n=32)$ & 26 & $4(17.4)$ \\
\hline 7 days $(n=23)$ & 19 & \\
\hline
\end{tabular}

the intensive care unit. This had also been noted by Njall et al. in Cameroon in 2011; they reported a primary admission frequency of $70.5 \%$ against $29.9 \%$ of referral [6]. This is evidence of the fact that parents were concerned with the severity of their relatives' clinical picture; therefore they decided to consult directly an appropriate health center. No patient benefitted from medical transport in our cohort. Other African researchers had made the same point [7] [8]. The lack of medical transportation equipment in the Region and the ignorance of its advantages due to misinformation may explain but not justify that attitude which worsens patients prognosis for lack of pre-hospital care and increases mortality rate. The leading cause of coma reported in our investigative work is traumatic brain injury resulting from accidents occurred on the public road. This observation was made by some African authors, especially Diallo et al. in Mali and Sanou et al. in Burkina-Faso; they respectively reported rates of $78.6 \%$ and $92.45 \%$ [9] [10]. Indeed, the research work of these authors focused on traumatic brain injuries mostly caused by accidents occurred on the public road. This raises the complex issue of ever-growing road traffic in African towns. The non-fulfillment of road traffic regulations and particularly the refusal to wear bike helmet expose cephalic pole to shocks causing multiple injuries the main clinical expression of which is coma. The set-up of compulsory helmet wearing for motorcyclists which has become a reality in Benin cities would contribute to reduce the frequency of cephalic pole traumas and their consequences.

Most of our patients had been admitted in the intensive care unit no later than 24 hours. They were mainly persons with traumatic brain injury urgently transported by firefighters. A long waiting time for consultation was noted in the group of non-traumatic comas where initial strategy consisted in consulting traditional healers or healthcare practices before considering the services of university hospital only when therapy fails. This attitude is a factor that worsens clinical presentation; it is also a factor associated with the extension of therapeutic management time. It would be due to several elements:

- The trust placed in those traditional practitioners/healers supposed to have a healing power.

- The population's cultural interpretation of the pathology's nature (it believes that coma is caused by divinities).

- The low socioeconomic status of the population who considers itself as unable to pay for the costs of treatment proposed by modern medicine.

Traumatic comas were most represented in our cohort. This remark was made by Antagana et al. who reported in Yaoundé a higher admission frequency of traumatic brain injuries among which $24.6 \%$ were patients with severe multiple injuries [11]. By contrast, in the University Teaching Hospital of Nantes (France), Asseray et al. found in their research works conducted in the emergency information division a low rate of cranial traumas (7\%) [12]. As regards non-traumatic comas, the three main etiologies observed in our study were vascular comas followed by infectious comas and metabolic comas. The same etiologies were reported in the study carried out by Kammoun et al. in Tunisia with the difference that metabolic comas come in second place after 
vascular comas [3]. In Europe, Asseray et al. had noted that vascular comas were more common [13] whereas Fougeras et al. found out toxic coma as the leading cause [12].

\subsection{Evolution and Prognostic Data}

The average length of stay in the intensive care unit demonstrated in our cohort was lower than the ones reported by Kambola et al. in Democratic Republic of Congo (9.3 days) [14] and Sène Diouf et al. in Senegal (10.8 \pm 11 days) [15]. This remark is evidence of the severity of patients' clinical condition on admission, thus leaving the nursing staff with very few possibilities of care; this explains the high death rate recorded before 48 hours.

The mortality rate pointed out in our study was lower than the one obtained by Moussa in Cotonou in 2007 (58.7\%) [5]. As far as traumatic comas are concerned, 20.9\% of our patients had died. This rate is near the one reported by Tomta et al. (19.11\%) [7], but it is however below 52.2\% reported by Abdelhamid et al. in Morocco [16]. Nevertheless, we registered $36.8 \%$ of deaths in non-traumatic comas. This rate is above $32.5 \%$ found by Ibekwe et al. in Nigeria [17]. Among the 67 patients (67\%) transferred to the intensive care unit, 61 were independent with one Rankin $\leq 2(61 \%)$. The latter showed mild disability on discharge from hospital and were unable to carry out efficiently all previous activities. The rest of the patients (6\%) was dependent with one RANKIN > 2 (6\%) and therefore require some helps (moderate disability). This remark is associated with the sequelae induced by neurological injuries demonstrated on admission.

The analysis of socio-demographic data like age, sex, indigenous therapy and/or attendance of healthcare practices does not find correlation with vital prognosis. However, it should be noted that in 5 patients aged above 76 years, three had died; hence this points out the fragility of those old persons. Mortality was associated with depth of coma $(p=0.01)$, high OSSI $(p=0.02)$, existence of pupillary abnormality $(p=0.00)$, severe neurological deficit $(p=0.00)$, hyperglycemia $(p=0.02)$, occurrence of hyperthermia $(p=0.01)$, systolic blood pressure $(p=0.03)$ and/or diastolic blood pressure $(p=0.03)$ or with acute respiratory failure on admission $(p=$ $0.03)$. Those different correlations were made by several authors. Thus, depth of coma was also an element of poor vital prognosis as some researchers emphasized it [3] [18] [19]. Outpatient simplified severity index (OSSI) is a severity factor. The higher it is, the more survival rate decreases. So, for Prudhomme, above 8 (OSSI > 8) survival rate declines. The higher OSSI is the higher mortality is [20]. The existence of pupillary abnormality was a poor prognostic factor as noted in literature. It is often the testimony of uncal herniation, mesencephalon or occipital injury and even of cerebral anoxia. This therefore explains the often unfavorable evolution of the clinical picture. As found in our study, the severer neurological deficit was, the higher death risk was. Soumaré et al. in Senegal [2], Koton et al. in Israel [21], Nedeltchev et al. [22] in Switzerland made the same remark. In our investigative work the only biological element which has a correlation with death occurrence was glycemia. This remark is confirmed by many researchers [22] [23]. The role of hyperthermia in death occurrence had been demonstrated by Rogelio et al. in Spain [24], Saini et al. in Canada [25], Le Craig et al. in the United Kingdom [26]. As regards blood pressure, Nedeltchev et al. in Switzerland in 2010 [22], Ossou-Nguiet et al. in Brazzaville in 2011 [23], Raveloson et al. in Madagascar [18] also made the following conclusions. Low blood pressure in the absence or presence of self-regulation of brain blood flow (BBF) vis-a-vis average blood pressure (ABP) implies a deleterious brain hypoxia for the patients. As well, high blood pressure may increase vasogenic component of brain edema when its level exceeds the limits of self-regulation. Respiratory failure demonstrated on admission is a poor prognostic factor. This remark is identical to the ones made by several authors [3] [6]. Actually, respiratory failure could progress towards brain hypoxia thus impeding glucose metabolism. This will result in lactate production which, above $4 \mathrm{mmol} / \mathrm{L}$, would cause increased death risk. Besides, hyperventilation reduces partial pressure of carbon dioxide in arterial blood and causes changes in blood $\mathrm{pH}$ (respiratory alkalosis). This questions the supply of oxygen to the brain by reducing brain blood flow. The study was conducted in an intensive care unit with no internal pharmacy so as to provide quick care for patients. The systematic consequence of this situation is the issuance of medical prescription to all patients admitted in the healthcare units. Care is thus delayed by several factors as explained in our results, thus causing death cases. Therefore, the hospital directorate should to do everything to make drugs actually available in healthcare units. This availability of drugs would assuredly contribute to improve care for patients with reduction of mortality rate as a result.

The main limit of this study is its design. The analytical study such as cohort study or case-control study is the best design to approach the etiological factors for poor prognosis. Other limitation is the lack of the paraclinic test (CT-scan, biological test, EEG...) due to their affordability. 


\section{Conclusion}

Coma is a common pathological entity in clinical medicine. Its positive diagnosis is easy, but etiologic research is not easy. In hospital mortality is high and influenced by a set of factors. Considering those factors in care strategies can improve their prognosis.

\section{References}

[1] Mathé, J.F., Richard, I. and Rome, J. (2005) Santé publique et traumatismes et traumatisme crâniens graves : Aspects épidémiologiques et financiers, structures et filières de soins. Annales Françaises d'Anesthésie et de Réanimation, 24, 688-694. http://dx.doi.org/10.1016/j.annfar.2005.03.029

[2] Soumaré, M., Seydi, M., Diop, S.A., Fall, N., Niang, K.N., Sidya, K.I., et al. (2007) Epidémiologie, étiologie et pronostic des comas infectieux de l'adulte à Dakar (Sénégal). Revue du CAMES, 5, 17-24.

[3] Kammoun, L., Chaari, A., Chakroun, O., Ksibi, H., Rejeb, I. and Rekik, N. (2012) Les facteurs pronostiques des comas non traumatiques. 40ème Congrès national d'anesthésie et de réanimation, Paris, 20 January 2012, SP204.

[4] Konan, K.J., Babo, C., Ayé, Y.D., Bouh, J., Kouamé, Y.S., Soro, L., et al. (2012) Aspects épidémiologiques des admissions dans le service de réanimation du CHU de Yopougon au cours du conflit armé post-électoral en Côte d'Ivoire. Revue d'Anesthésie-Réanimation et de Médecine d'Urgence, 18, 1-2.

[5] Moussa, H. (2007) Les états comateux dans le Service Polyvalent d'Anesthésie et Réanimation (SPAR): Épidémiologie, pronostic et complications. Thèse Méd, $\mathrm{N}^{\circ} 1331$, Cotonou, $120 \mathrm{p}$.

[6] Abdelhamid, H., Mina, E., Ibtissam, C., Rachid, R., Amra, Z. and Mohamed, A.S. (2014) Coagulopathie aigue précoce des traumatismes crâniens graves: Mortalité et facteurs pronostiques. Pan African Médical Journal, $17,107$.

[7] Tomta, K., Djibril, M.A., Mouzou, T., Sama, H., Chobli, M. and Ahouangbevi, S. (2011) Traumatisme crânioencéphalique au Centre Hospitalier Universitaire Tokoin de Lomé (TOGO). Journal de la Recherche Scientifique de l'Universite de Lome (Togo), 13, 47-57.

[8] Asseray, N., Dary, M., Gueffet, I., Batard, E., Trewick, D., Arnaud, G., et al. (2004) Recensement des comas graves dans un service d'accueil urgence: Etiologie et devenir des patients. Journal Européen des Urgences, 17, 42. http://dx.doi.org/10.1016/s0993-9857(04)97117-8

[9] Raveloson, N., Rajaonera, A.T., Ramorasata, J.A., Rakotoarivony, S.T., Randrimiarana, J.M. and Sztark, F. (2009) Facteurs de mauvais pronostic des comas non traumatiques. Revue d'Anesthésiologie et de Médecine d'Urgence, 1, 2327.

[10] Sanoussi, S., Ali, A., Laouali, H., Assoumane, I., Chaibou Maman, S. and Baoua, M. (2013) Traumatisme crânien et dysfonctionnements antéhypophysaires. A propos de 33cas: Profil évolutif sur 6mois. Neurochirurgie, 59, 178-182. http://dx.doi.org/10.1016/j.neuchi.2013.08.004

[11] Napon, C., Sawadogo, R., Lompo, L., Dabilgou, A.A., Dravé, A. and Kaboré, J. (2011) Facteurs de risque et étiologies de l'accident vasculaire cérébral ischémique du sujet jeune au Burkina Faso. Médecine d'Afrique Noire, 58, 541-544.

[12] Diallo, A., Keita, M., Samaké, B.M., Togo, A., Diani, N. and Kanikomo, D. (2012) Intérêt de la sédation du traumatisé crânien. Revue Afrique d'Anesthésie-Réanimation et de Médecine d'Urgence, 17, 1-4.

[13] Bamouni, Y.A., Lougue/Sorgho, C.L., Cisse, R., Zanga, S.M. and Tapsoba, T. (2006) Aspects épidémiologique, clinique et évolutif des accidents vasculaires cérébraux ischémiques. Médecine d’Afrique Noire, 53, 349-350.

[14] Najall, P.C., Bita, A.A., Beyiha, G., Tazemda, B., Sume, E.G. and Binam, F. (2012) Facteurs pronostics des traumatisés graves de la route admis au service de réanimation de l'hôpital Laquintinie de Douala. Revue Afrique d'Anesthésie-Réanimation et de Médecine d'Urgence, 17, 1-10.

[15] Beye, S.A., Malle, K.K., Djibo, M.D., Goïta, D., Ouattara, K., Dembele, D., et al. (2010) Prise en charge des traumatisés crâniens au service d'accueil des urgences: Problématiques et perspectives. Médecine d'Afrique Noire, 57, 351-356.

[16] Sanou, J., Bonkoungou, P.Z., Kinda, B., Kientéga, N.H., Da, C.S. and Traoré, S.S. (2012) Traumatismes crâniens grave: Aspects épidémiologiques, cliniques et facteurs limitant la réalisation de la tomodensitométrie cérébrale par rapport aux prescriptions. Revue Afrique d'Anesthésie-Réanimation et de Médecine d'Urgence, 17, 1-7.

[17] Atangana, R., Eyenga, V.C., Binam, F. and Sosso, M.A. (2009) Facteurs prédictifs de mortalité chez les polytraumatisés à Yaoundé. Médecine d'Afrique Noire, 56, 338-340.

[18] Fougera, O., Benattia, C., Leroux, C., Julié, V., et al. (2004) Epidémiologie des comas graves recueil d’un SAMU. Evaluation des pratiques en SAMU-SMUR JEUR, 17, 99-102.

[19] Placide, K.K., David, M.K., Axel, M.K., Prosper, K.M., Marcellin, B. and Olivier, M. (2014) Acidocétose diabétique chez l'adulte à l’Hôpital Sendwe Lubumbashi: A propos de 51 cas. Pan African Médical Journal, 17, 324. 
[20] Sène, D., Mapoure, N.Y., Ndiaye, M., Mbatchou, N., Touré, K., Thiam, A., et al. (2008) Survie des accidents vasculaires cérébraux comateux à Dakar (Sénégal). Revue Neurologique, 164, 452-458. http://dx.doi.org/10.1016/j.neurol.2008.01.007

[21] Abdelhamid, H., Mina, E., Ibtissam, C., Rachid, R., Amra, Z. and Mohamed, A.S. (2014) Coagulopathie aigue précoce des traumatismes crâniens graves: Mortalité et facteurs pronostiques. Pan African Médical Journal, 17, 107.

[22] Ibekwe, R.C., Ibekwe, M.U., Onwe, O.E., Nnebe-Agumadu, U.H. and Ibe, B.C. (2011) Non-Traumatic Childhood Coma in Ebonyi State University Teaching Hospital, Abakaliki, South Eastern Nigeria. Nigerian Journal of Clinical Practice, 14, 43-46. http://dx.doi.org/10.4103/1119-3077.79239

[23] Ossou-Nguiet, P.M., Gombet, O.A.M., Ellenga, F.B., Otiobanda, G.F. and Mahoungou-Guimbi, K.C. (2013) Facteurs de mortalité des accidents vasculaires cérébraux aux CHU de Brazzaville. Revue Afrique d'Anesthésie-Réanimation et de Médecine d'Urgence, 18, 7-28.

[24] Prudhomme, C. (2013) Urgences. 6th Edition, Maloine, Paris, 1-531.

[25] Koton, S., Tanne, D., Green, M. and Bornstein, N. (2010) Ischemic Stroke: Data from the First National Acute Stroke Israeli Survey. Neuroepidemiology, 34, 90-96. http://dx.doi.org/10.1159/000264826

[26] Nedeltchev, K., Renz, N., Karameshev, A., Haefeli, T., Brekenfeld, C., Meier, N., et al. (2010) Predictors of Early Mortality after Acute Ischemic Stroke. Swiss Medical Weekly, 140, 254-259. 